ENCYCLOPÉDIE Encyclopédie berbère

BERBERE

18 | 1997

18 | Escargotière - Figuig

\title{
Etranger
}

Extérieur (chez les Touaregs)

\section{H. Claudot-Hawad}

\section{OpenEdition}

Journals

Édition électronique

URL : http://journals.openedition.org/encyclopedieberbere/2008

DOI : $10.4000 /$ encyclopedieberbere.2008

ISSN : 2262-7197

\section{Éditeur}

Peeters Publishers

\section{Édition imprimée}

Date de publication : 1 août 1997

Pagination : 2703-2706

ISBN : 2-85744-948-8

ISSN : $1015-7344$

Référence électronique

H. Claudot-Hawad, «Etranger », Encyclopédie berbère [En ligne], 18 | 1997, document E46, mis en ligne le 01 juin 2011, consulté le 24 septembre 2020. URL : http://journals.openedition.org/ encyclopedieberbere/2008; DOI : https://doi.org/10.4000/encyclopedieberbere.2008

Ce document a été généré automatiquement le 24 septembre 2020.

(c) Tous droits réservés 


\title{
Etranger
}

\author{
Extérieur (chez les Touaregs)
}

\section{H. Claudot-Hawad}

1 Contrastant avec la vision essentialiste des rapports humains, les Touaregs offrent, à travers leur classification des mondes de l'intérieur et de l'extérieur, une appréhension dynamique et interrelationnelle de la culture et de l'identité. Dans la cosmogonie touarègue*, tout être, toute chose, tout élément, apparaît mobile, engagé dans une succession de cycles qui reproduisent le mouvement de l'univers. La culture et les personnes qui l'endossent accomplissent à leur tour un parcours jalonné d'étapes différentes. Ainsi conçue, la culture se présente comme un ensemble de valeurs et de savoirs dont les contours et la forme évoluent en fonction des rapports établis avec l'environnement.

2 L'« extérieur » (essuf), c'est-à-dire le monde étrange et non domestiqué, est vu à la fois comme une menace spirituelle mais aussi comme l'élément nécessaire à toute progression de soi. Il est l'éperon de la marche nomade qui exige le franchissement infini de nouvelles étapes, jusqu'à l'harmonie c'est-à-dire jusqu'à la disparition des contradictions et des oppositions.

3 La manière dont la philosophie touarègue envisage l'altérité est bâtie sur cette appréhension du monde dont les aspects, éphémères, annoncent déjà les mutations à venir.

4 Des catégories conceptuelles différentes s'appliquent aux étrangers qui se trouvent en pays touareg et aux habitants des contrées étrangères. Le terme général qui désigne l'étranger de passage est amagar, imagaren, de la racine égar: "étaler (la natte, le tapis) ", c'est-à-dire "accueillir, donner l'hospitalité ». En effet cette appellation signifie également «l'hôte, l'invité ». Le voyageur étranger qui n'est pas un amagar à recevoir et à protéger est nécessairement un ennemi (azengu, ahengu, ashengu selon les parlers).

5 Concernant les populations étrangères voisines, c'est en fonction des formes multiples d'échange établies que s'élabore une série d'appellations classifiant et définissant ces espaces humains de l'extérieur. 
6 Par exemple, dans l'Aïr, pour désigner les populations qui n'ont avec les Touaregs aucun type de rapports sinon occasionnel et le plus souvent agressif, le terme général est ewenanen (sing. awenan), connotant la sauvagerie et la barbarie. Les iwenanen apparaissent sous cet angle repliés sur leur culture et leur langue, refusant toute liaison avec les autres (M. Rodinson fait remarquer l'analogie phonétique entre ce terme et l'appellation ancienne utilisée par les Égyptiens pour désigner les Grecs). Igoriten (sing. agori) est également péjoratif et s'applique aux habitants encore plus lointains des zones tropicales avec lesquels les Touaregs n'ont de contact qu'à travers les iwenanen.

7 Par contre, dès que s'instaurent des rapports réguliers sur le plan économique, politique ou social, qu'ils soient positifs ou négatifs, les diverses communautés entrent dans une structure de complémentarité et deviennent des partenaires culturellement reconnus, dotés d'appellations nuancées.

8 Trois catégories de ces « extérieurs » déjà défrichés sont distinguées : les izaghan (sing. azgha) désigne au sud-est du pays touareg les populations de culture Bornou du Lac Tchad jusqu'au Soudan, avec lesquelles se sont nouées des relations très anciennes. Ensuite viennent au sud-ouest les ihatan (sing. éhéti) qui concernent les Songhay et tous les peuples qui sont placés dans leur orbite. Enfin, on considère que les itéfénen (sing. atéfen) qui dénomme les Haoussa établis au sud sont situés dans une étape de proximité culturelle encore plus grande: leur culture a en effet intégré certains éléments berbères, mais en les réinterprétant pour son usage personnel et non en les copiant ou en les substituant à ses propres valeurs comme l'ont fait les deux précédentes catégories.

9 Le métissage des cultures comporte plusieurs degrés. L'état où ne se produit aucune affinité, aucune interaction, aucune symbiose, est celui de la sauvagerie (tawenana). Par contre, lorsque certains traits sont empruntés à une autre culture et juxtaposés ou substitués aux siens propres, on devient bagermi : ce terme s'applique par exemple à un Touareg qui vit en pays haoussa et mélange les deux cultures sans en avoir encore réalisé une synthèse originale. Enfin, ceux qui parviennent à accomplir cet amalgame en le métamorphosant en une véritable culture, nouvelle, créative et dynamique, sont appelés tikruru ou tekruru selon les régions (dans le parler de l'Aïr, le $t$ suivi de $i$ est chuinté et se réalise phonétiquement tsh: on prononce donc tshikuru). Si cette appellation désigne souvent les Peuls, elle ne s'applique cependant qu'à une partie d'entre eux. Par exemple, les Peuls Bororo qui ont conservé le mode de vie nomade ancien, ne sont pas considérés comme tikruru: ils sont appelés ifellanen, et perçus comme des frères en révolte, des « métamorphosés » par rapport à la culture d'origine qui serait commune aux Peuls, aux Berbères, aux Arabes, aux Juifs et aux Ethiopiens.

D'un point de vue touareg, en effet, les tikruruten sont ceux qui font le lien entre les peuples, comme par exemple les grands commerçants, les grands caravaniers qui relient le nord au sud, les lettrés musulmans, les médecins qui associent les connaissances de la Méditerranée, de l'Afrique Noire et de l'Orient, les urbains qui vivent à la croisée de plusieurs cultures et les ont toutes intégrées... Le terme peut servir à désigner aussi bien certains Woloff, Dioula, Peuls, Touaregs, Arabes, Toucouleurs (qui serait une transcription française du berbère Tekrur), Haoussa ou Bounou..., tout comme des non sahéliens comme les Mossis et les Bambaras, qui incarnent cette culture intermédiaire et synthétique, étoffée par la faculté de s'exprimer couramment en plusieurs langues. 
11 Alors que les termes de Bagermi ou Bagarmi et de Tekrur ou Takrur apparaissent d'un point de vue touareg comme des concepts identitaires qui ne sont ni ethniques, ni géographiques, mais se rapportent à des paliers de croisement culturel et à des fonctions d'intermédiaires entre les sociétés, ils sont donnés dans différents manuscrits arabes anciens, provenant des bibliothèques de l'Afrique de l'ouest, comme des noms propres désignant soit des régions, des territoires et parfois des villes, soit des peuples à la localisation et aux contours souvent ambigus et contradictoires.

12 Au sud de la limite des Tikruru, seuls les Yoruba avec lesquels existent des liens économiques anciens à travers le pays haoussa sont dénommés par leur nom propre. Les Yoruba sont considérés comme un autre type de symbiose culturelle orientée vers les pays tropicaux et gratifiés à ce titre de la considération que l'on porte aux cultures « en marche ». Enfin, ils fournissent également quelques tikruru notamment grâce à leurs ambassades, installées dans les comptoirs sahariens et sahéliens, et à leurs nombreux colporteurs.

13 Les Toubous à l'est du pays touareg ont un statut spécial : ils sont dénommés ikardan (sing. akarda). Bien que les rapports avec eux soient généralement conflictuels, les mariages sont possibles. Ils ne sont pas iwenanen et cependant ils pouvaient autrefois en cas de guerre être réduits en esclavage, alors que cela ne se pratiquait ni pour les Peuls, ni pour les Tikruru, ni pour ceux qui entretenaient des rapports réguliers avec les Touaregs ou se trouvaient placés sous leur protectorat.

14 Parmi les cercles culturels les plus proches, figurent non seulement les Peuls, mais aussi les Maures et les Arabes.

Téshlag s'applique aux Maures, berbères islamisés appartenant à l'origine, pense-t-on, à la même famille que les Touaregs. Deux racines possibles sont évoquées pour ce terme. La première se réfère au mot ashalag qui signifie «porter son pantalon en bandoulière ». L'autre hypothèse le fait dériver de asalag qui veut dire " écarter, mettre de côté ", signifiant que les Maures ont suivi un chemin divergeant par rapport aux Touaregs et qu'ils sont aujourd'hui mis à part, distincts de ces derniers. Dans les deux cas, c'est la perte des valeurs, des références et de l'honneur touaregs qui est soulignée.

Elgabliten (sing. elgabli) désigne littéralement ceux qui s'orientent à l'est vers la Mecque (elqabla en arabe) : cette appellation concerne les Arabes et les Maures qui ont conservé leur mode de vie nomade, mais ont perdu beaucoup de leur culture ancienne - qu'ils partageaient à l'origine avec les Berbères -, et qui ont adopté la langue arabe. Elgabliten connote également une certaine rusticité ainsi que l'absence de racines. La langue et la culture de tous ces Berbères arabisés est désignée par le terme elgelgalya, associé à l'« embrouille» (egelgel) et qui connote également le savoir et les manières de ceux qui imitent un modèle étranger sans parvenir à le maîtriser (plus récemment, on les appelle aussi aniten, déformation d'un mot arabe signifiant « semblant de » ou « simili » Arabes).

17 Parmi eux se distinguent les Araben arabawadan, c'est-à-dire les «Arabes arabe-filsd'Adam », autrement dit, les Arabes " humains ». L'appellation de Araben arabawadam s'applique à tous les arabophones sahariens qui vivent parmi les Touaregs et étaient autrefois agrégés à leur clientèle politique, comme certains campements Maures, Kounta, Chambas... Ces derniers sont d'ailleurs parfaitement bilingues.

18 Enfin, Araben win jaghamjagham sert à nommer ceux qui en parlant émettent des sons gutturaux (rendus par l'onomatopée jaghamjagham) et qui diffèrent des Touaregs non 
seulement par la langue et la culture mais aussi par le mode de vie, les manières, l'aspect (par exemple, ceux qui ne se rasent pas les poils au dessus de la lèvre supérieure et portent la moustache)... Ce terme sert souvent à désigner les Chambas et les arabophones du nord.

Si les symbioses avec les cultures sahéliennes et méditerranéennes sont nommées, par contre les récents produits culturels nés du contact avec l'Europe tels que les soldats engagés dans l'armée française, les scolarisés, les fonctionnaires, les prostituées..., tous sont rangés dans la catégorie des guméten, c'est-à-dire des "goumiers ». Y sont inclus également les nomades désorganisés qui s'agglutinent autour des villes pour recevoir l'aide internationale, bref tous ceux qui sont entrés dans la logique étatique coloniale et postcoloniale et qui s'y appuient. La culture des guméten apparait souvent comme une sorte de contrefaçon grossière, figée dans le mimétisme de l'extérieur et privée de toute capacité d'extension personnelle.

Plusieurs paliers de symbioses culturelles marquent ainsi l'ascension vers l'état de tikruru, où dominent l'esprit d'initiative, l'innovation, l'art de tirer parti de n'importe quelle situation, la possibilité de comprendre tous les enjeux, la faculté de relier et de souder la mosaïque des peuples d'Afrique. Mais pour le bon équilibre de l'ensemble, il n'est pas souhaitable que tout le monde deviennent tikruru. En effet, l'opposition entre soi et les autres est également porteuse de dynamisme. L'« intérieur » n'évolue que s'il est confronté à l'« extérieur » qui en est le contrepoids indispensable. Ces ancrages inamovibles entre lesquels les tikururu tissent constamment des liens, suivent euxmêmes une progression dans leur direction propre. Même s'ils n'assimilent pas rapidement l'extérieur, ils sont aiguillonnés par sa présence et parviennent à le domestiquer et à le tamiser pour finalement le rendre adoptable.

Si tous devenaient tikruru, autrement dit si les oppositions et les antagonismes culturels s'estompaient complètement, le danger serait d'aboutir à une mouvance précipitée, sans seuil ni étapes à franchir, bref à une marche trop rapide qui deviendrait glissante et tourbillonnante.

L'excès inverse, l'absence de tikruru, conduirait à une égale catastrophe : il n'y aurait plus de relations entre les cultures, les savoirs, les identités qui se figeraient, se retréciraient, se recroquevilleraient et finalement s'éteindraient.

La même vision dynamique de l'univers s'applique à l'organisation interne des Touaregs où les différentes catégories sociales sont perçues comme des éléments « en route » lancés sur les parcours successifs qui conduisent finalement à la fusion avec le cosmos.

Par exemple, dans l'itinéraire social, les esclaves (iklan), une fois qu'ils avaient acquis la culture touarègue, devenaient des "affranchis " (ighawelen), entrant dès lors dans le cycle des hommes libres en marche vers l'accomplissement de soi, c'est-à-dire la noblesse. Cette théorie pose le caractère éphémère de la hiérarchie sociale et implique l'infinie rotation des rôles que la colonisation a interrompue.

Enfin, dans le domaine même de la poésie, l'un des modes privilégiés d'expression culturelle chez les Touaregs, se retrouvent des genres littéraires qui incarnent chacun des étapes de cet essor vers l'extérieur : la poésie classique, toute pétrie des valeurs de l'intérieur, s'oppose ainsi aux isebelbilen, glossolalie d'action, qui mêle à la langue touarègue des mots ou des grommellements aux assonances étranges, symbolisant le 
monde de l'extérieur qui vient doper, stimuler, provoquer et éperonner le monde de l'intérieur.

On le voit, ces conceptions vont à l'encontre des thèses qui tracent entre les cultures des frontières infranchissables, débouchant par exemple dans leur appréciation du changement sur des notions de "perversion" ou de "déviation" opposées à la " pureté » ou à l'« authenticité » présumées originelles.

Loin de ce schéma figé, les différentes formes de synthèses culturelles apparaissent chacune, dans cette perspective, comme un palier indispensable dans l'organisation du cheminement universel, car sans altérité, pas de progression et sans symbiose, pas d'ascension (voir Hawad, 1987).

\section{BIBLIOGRAPHIE}

ALOJALY GH., Lexique touareg-français, édition et révision K.-G. Prasse, Copenhague, Akedemisk Forlag, 284 p., 1980.

BERNUS E., « Les touaregs et les autres ", A la croisée des études libyco-berbères, Mélange offert à L. et P. Galard, pp. 567-573.

CLAUDOT-HAWAD H., Les fibres synthétiques de la culture, Regard Touareg, Autrement.

HAWAD, Chants de la soif et de l'égarement Édisud, Aix-en-Provence, 1987.

FOUCAULD CH. DE,Dictionnaire de noms propres, Alger, 1940.

FOUCAULD CH. DE,Dictionnaire touareg-français, Paris, Imp. Nat., 1951-1952.

INDEX

Mots-clés : Ethnologie, Famille, Habitation, Sahara, Touareg 